eCommons@AKU

March 2005

\title{
Olfactory neuroblastoma: a case report and review of the literature
}

Shehzad Ghaffar

Aga Khan University, shezad.ghaffar@aku.edu

Iftikhar Salahuddin

Aga Khan University, iftikhar.salahuddin@aku.edu

Follow this and additional works at: https://ecommons.aku.edu/ pakistan_fhs_mc_surg_otolaryngol_head_neck

Part of the Otolaryngology Commons, and the Surgery Commons

\section{Recommended Citation}

Ghaffar, S., Salahuddin, I. (2005). Olfactory neuroblastoma: a case report and review of the literature. Ear, Nose, and Throat Journal, 84(3), 150-152.

Available at: https://ecommons.aku.edu/pakistan_fhs_mc_surg_otolaryngol_head_neck/79 


\title{
Olfactory neuroblastoma: A case report and review of the literature
}

\author{
Shehzad Ghaffar, FCPS (Pak.), FRCS (Ire.); Iftikhar Salahuddin, MD, FRCS (Can.)
}

\begin{abstract}
Malignant tumors of the nasal cavity are rare. We report the case of an elderly woman who consulted us with a 4year history of progressive nasal obstruction, occasional epistaxis, facial pain, and watering of the eyes. A diagnosis of olfactory neuroblastoma was established by histopathology and confirmed by immunohistochemistry. On staging, the mass was classified as a Kadish stage B tumor. The mass was excised via a lateral rhinotomy approach, and the tumor was peeled away completely from the cribriform plate with endoscopes. The patient underwent postoperative radiation, and she was free of recurrence at follow-up 15 months later.
\end{abstract}

\section{Introduction}

Malignant tumors of the nasal cavity are rare. Olfactory neuroblastomas (esthesioneuroblastomas) account for only $6 \%$ of these neoplasms. ${ }^{1}$ Fewer than 1,000 cases have been reported in the literature since this tumor was first described more than 75 years ago. ${ }^{2}$ These lesions can be easily missed because the presenting symptoms mimic those of benign tumors of the nose. They are often discovered incidentally during septoplasty or polypectomy. ${ }^{3}$ Because olfactory neuroblastomas are so uncommon, few data exist with respect to optimum management strategies, although diagnostic and treatment modalities have improved over the past 2 decades..$^{3-5}$ Treatment recommendations range from a minimally invasive approach ${ }^{6}$ to craniofacial resection combined with radiotherapy. ${ }^{7}$

In this article, we report a new case of olfactory neuroblastoma.

\section{Case report}

A 67-year-old woman consulted us with a 4-year history of progressive nasal obstruction, occasional epistaxis,

From the Section of Otolaryngology-Head and Neck Surgery, Department of Surgery, Aga Khan University Hospital, Karachi, Pakistan.

Reprint requests: Dr. Shehzad Ghaffar, Senior Instructor, Section of Otolaryngology-Head and Neck Surgery, Department of Surgery, Aga Khan University Hospital, Stadium Rd., Karachi-74800, Pakistan. Phone: 92-21-493-0051, ext. 4770 or 4767; fax: 92-21-493-2095; e-mail:sgm@akunet.org facial pain, and watering of the eyes. On rhinoscopy, a polypoid mass was seen in the roof of her nose; the mass was not attached to the septum or lateral wall. Her vision in both eyes was normal, and her eye movements were unrestricted. Findings on the remainder of the head and neck examination were unremarkable. The patient had undergone two surgical procedures elsewhere- 3 and 1 years prior to presentation - during which intranasal excision of the mass had been attempted. These operations ultimately failed because of an incomplete removal of the mass and a lack of postoperative radiotherapy.

We performed an intranasal biopsy with local anesthesia, which was completed with minimal bleeding. On histopathologic analysis, the tumor was identified as an olfactory neuroblastoma (figure 1, A). This finding was confirmed by immunohistochemistry, which was positive for chromogranin, synaptophysin, neuron-specific enolase, and neurofilament (figure 1, B). Computed tomography (CT) confirmed that the tumor arose from the cribriform area; no intracranial extension was seen (figure 2, A). The ipsilateral anterior and postethmoid cells were involved, but the maxillary and sphenoid sinuses were free of tumor. The mass was removed via a lateral rhinotomy approach, and the tumor was peeled away completely from the cribriform plate with endoscopes.

Two weeks after surgery, the patient received 6,000 cGy of radiation in 30 fractions. At follow-up 15 months later, she was free of recurrence (figure 2, B).

\section{Discussion}

Olfactory neuroblastomas arise from olfactory neuroepithelium, which extends from the roof of the nose to the area of the superior turbinates and a portion of the nasal septum. ${ }^{7}$ From there, they can readily extend into the cribriform plate of the ethmoid sinus. Most of the cases described in the literature involved adults, but 1 case has been reported in a child as young as 2 years of age. ${ }^{8}$

Symptoms. The most common symptoms of olfactory neuroblastoma are nasal obstruction, epistaxis, and headache (patients with extensive tumors may have orbital symptoms such as proptosis and excessive lacrimation). ${ }^{9}$ Because most of these symptoms are similar to those of benign nasal disease, olfactory neuroblastoma is often 

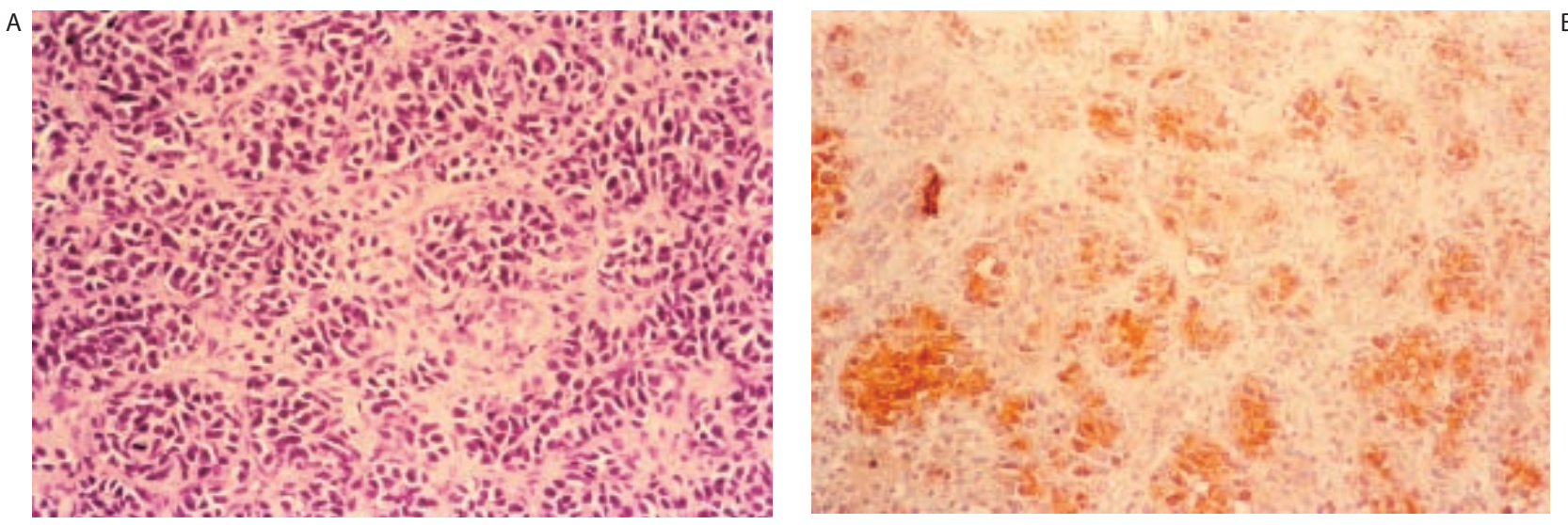

Figure 1. A: Histopathology demonstrates compact nests of uniform small cells with round basophilic nuclei and scant cytoplasm $(H \& E$, original magnification $\times 20)$. B: The histopathology findings are confirmed on immunohistochemistry, which is positive for chromogranin, synaptophysin, neuron-specific enolase, and neurofilament.

missed during its early stages and not diagnosed until it has reached an advanced stage.

Investigation. High-resolution $\mathrm{CT}$ and magnetic resonance imaging can be used as complementary investigations to precisely delineate the extent of the tumor and to define the involvement of the cribriform plate, anterior cranial fossa, and retromaxillary space. Endoscopic examination is essential for evaluating the extent of the tumor and for obtaining a biopsy specimen.

Microscopic analysis. The typical histologic appearance of an olfactory neuroblastoma includes the presence of characteristic cells separated into nests or compartments by fibrovascular septae, neurofibrillary intercellular matrices, and rosette formations. The histologic diagnosis is often confounded by the various arrangements of cells packed in sheets and by an architecture that is similar to many neurogenic tumors. Immunohistochemistry, however, can lead to a definitive diagnosis; this tumor is positive for neuroendocrine markers such as chromogranin, synaptophysin, neuron-specific enolase, and protein gene product $9.5 .{ }^{10}$

Staging. Because malignant lesions of the nasal cavity are so rare and because many different histologic types of tumors abound, no approved classification and staging system has been universally accepted.

- The Hyams classification (grades I through IV) is based on histologic differentiation; the grade IV designation is used to describe undifferentiated sinonasal carcinomas. ${ }^{11}$
- More well accepted is the Kadish classification system (stages A through C), which is based on the clinical spread of the tumor; stage A tumors are confined to the nasal cavity, stage B lesions involve the sinuses, and stage C masses involve the middle cranial fossa and the retrobulbar orbit. ${ }^{12}$ Reservations about the Kadish system are based on the premise that there are minimal differences in the biologic behavior of stage A, B, and C tumors. Nevertheless, tumors in each of these classifications behave differently with respect to progression and metastasis and, therefore, survival patterns are different.

- Biller et al introduced yet another classification system, which takes into account the size of the primary tumor and the presence or absence of regional and distant metastasis. ${ }^{13}$

Treatment. Surgical resection is the clear treatment of choice, but opinions vary as to its extent. Biller et al rec-
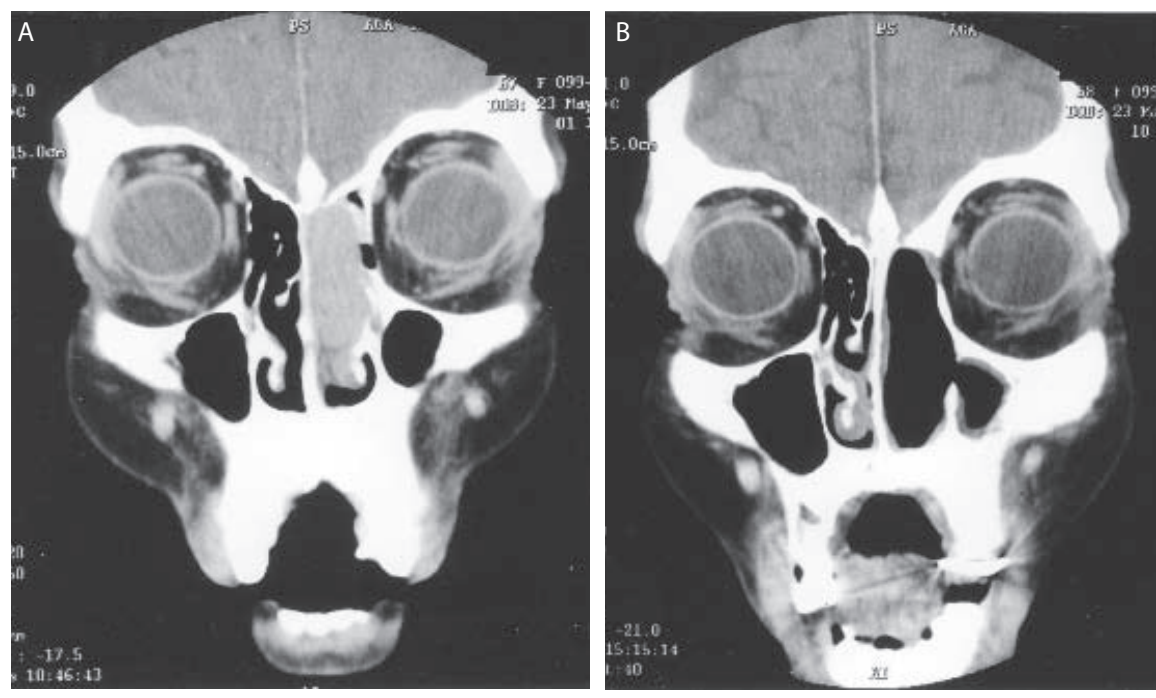

Figure 2. A: Preoperative CT shows the tumor in the cribriform area. B: At follow-up 15 months postoperatively, no sign of recurrence is evident. 
ommended craniofacial resection of all tumors, regardless of whether they invade the anterior cranial fossa or are confined to the nasal roof. ${ }^{13}$ They advocated resection of the dura over the cribriform plate, the olfactory bulb, the entire ethmoid labyrinth, and the anterior and posterior walls of the frontal sinus.

Preoperative irradiation appears to have no beneficial effect. Postoperatively, some authors have recommended radiotherapy only for advanced tumors, while others have suggested that it should be administered to all patients regardless of tumor stage. ${ }^{14}$ As of now, craniofacial resection combined with radiotherapy is considered the gold standard in the management of these tumors. ${ }^{15}$

Radical surgery of early lesions (Kadish stages A and B) is not performed at all centers. The results of transnasal endoscopic resection followed by radiation have been reported to be comparable to those of craniofacial resection. ${ }^{15}$ The pursuit of minimally invasive techniques has also led to the use of endoscopic resection of the tumor combined with stereotactic irradiation of the frontal skull base with a gamma-ray knife. ${ }^{6}$ This approach obviates the need for skin incisions and midface degloving and avoids the morbidity associated with conventional radiation therapy (e.g., optic neuropathy or retinopathy). Neck dissection is indicated only in the presence of nodes; elective dissection appears to be unnecessary.

The role of induction chemotherapy or concurrent chemoradiation therapy has not been defined. We know that olfactory neuroblastoma is chemosensitive and responsive to platinum-based agents, ${ }^{16,17}$ but chemotherapy is currently reserved for unresectable or recurrent tumors and for metastases.

Metastasis. Olfactory neuroblastomas have the potential to spread regionally. Neck metastasis can occur early in the disease or many years later. Rinaldo et al reviewed 320 cases at 15 centers and found that the incidence of both synchronous and metachronous neck metastases varied greatly, ranging from 5 to $100 \%$ (mean: $23.4 \%$ ). ${ }^{10}$ As is true for most head and neck cancers, cervical lymphadenopathy augurs poorly and increases the risk of distant metastasis, most often to bones. ${ }^{18}$

Recurrence. Despite aggressive therapy, recurrence can develop soon after treatment or even several years later. Researchers at the Mayo Clinic reported that $42 \%$ of local recurrences developed within 5 years postoperatively and that 1 case recurred as late as 10 years after surgery. ${ }^{19}$ In a review of 40 patients, Eden et al reported a recurrence rate of 55\%; two-thirds of these patients had locoregional disease, and $39 \%$ of them developed recurrences within 5 years of combined-modality (surgery plus radiation) treatment. ${ }^{20}$ Finally, researchers at the University of Iowa reported 5-and 10-year actuarial disease-free survival rates of 56 and $42 \%$, respectively. ${ }^{4}$

In conclusion, olfactory neuroblastoma requires ag- gressive surgical resection and radiation therapy. Patients must be followed carefully with the understanding that locoregional recurrences are common and may arise several years after treatment. The prognosis for long-term survival is poor.

\section{References}

1. Svane-Knudsen V, Jorgensen KE, Hansen O, et al. Cancer of the nasal cavity and paranasal sinuses: A series of 115 patients. Rhinology 1998;36:12-14.

2. Berger L, Luc H, Richard R. L'Esthesioneuroepitheliome olfactif. Bull Cancer (Paris) 1924;13:1410-21.

3. Argiris A, Dutra J, Tseke P, Haines K. Esthesioneuroblastoma: The Northwestern University experience. Laryngoscope 2003;113: 155-60.

4. Simon JH, Zhen W, McCulloch TM, et al. Esthesioneuroblastoma: The University of Iowa experience 1978-1998. Laryngoscope 2001;111:488-93.

5. Lund VJ, Howard D, Wei W, Spittle M. Olfactory neuroblastoma: Past, present, and future? Laryngoscope 2003;113:502-7.

6. Walch C, Stammberger H, Anderhuber W, et al. The minimally invasive approach to olfactory neuroblastoma: Combined endoscopic and stereotactic treatment. Laryngoscope 2000;110:635-40.

7. Broich G, PagliariA, Ottaviani F. Esthesioneuroblastoma:Ageneral review of the cases published since the discovery of the tumour in 1924. Anticancer Res 1997;17:2683-2706.

8. Woerner SJ, Lazerson J, Munn RJ, Turner EA. Olfactory neuroblastoma (esthesioneuroblastoma) in a 2-year-old boy. Pediatr Hematol Oncol 1986;3:167-74.

9. Levine PA, Gallagher R, Cantrell RW. Esthesioneuroblastoma: Reflections of a 21-year experience. Laryngoscope 1999;109: 1539-43.

10. Rinaldo A, Ferlito A, Shaha AR, et al. Esthesioneuroblastoma and cervical lymph node metastases: Clinical and therapeutic implications. Acta Otolaryngol 2002;122:215-21.

11. Hyams VJ. Tumors of the upper respiratory tract and ear. In: Hyams VJ, Batsakis JG, Michaels L, eds. Atlas of Tumor Pathology. 2nd series, fascicle 25. Washington, D.C.: Armed Forces Institute of Pathology, 1988:240-8.

12. Kadish S, Goodman M, Wang CC. Olfactory neuroblastoma. A clinical analysis of 17 cases. Cancer 1976;37:1571-6.

13. Biller HF, Lawson W, Sachdev VP, Som P. Esthesioneuroblastoma: Surgical treatment without radiation. Laryngoscope 1990;100:11991201.

14. Dulguerov P, Calcaterra T. Esthesioneuroblastoma: The UCLA experience 1970-1990. Laryngoscope 1992;102:843-9.

15. Casiano RR, Numa WA, Falquez AM. Endoscopic resection of esthesioneuroblastoma. Am J Rhinol 2001;15:271-9.

16. McElroy EA, Jr., Buckner JC, Lewis JE. Chemotherapy for advanced esthesioneuroblastoma: The Mayo Clinic experience. Neurosurgery 1998;42:1023-7, discussion 1027-8.

17. Wade PM, Jr., Smith RE, Johns ME. Response of esthesioneuroblastoma to chemotherapy. Report of five cases and review of the literature. Cancer 1984;53:1036-41.

18. Koka VN, Julieron M, Bourhis J, et al. Aesthesioneuroblastoma. J Laryngol Otol 1998;112:628-33.

19. Morita A, Ebersold MJ, Olsen KD, et al. Esthesioneuroblastoma: Prognosis and management. Neurosurgery 1993;32:706-14, discussion 714-15.

20. Eden BV, Debo RF, Larner JM, et al. Esthesioneuroblastoma. Longterm outcome and patterns of failure - The University of Virginia experience. Cancer 1994;73:2556-62. 